\title{
Trigeminal neuralgia recurrence: a comparison of microvascular decompression and percutaneous balloon compression: a five years follow-up study
}

Neuralgia do trigêmeo recorrente: uma comparação entre descompressão microvascular e compressão percutânea por balão: um estudo de acompanhamento de cinco anos

Jennyfer Paulla Galdino CHAVES'1, Tatiana Von Hertwig Fernandes DE OLIVEIRA', Alexandre Novick FRANCISCO', Mariana de Oliveira TRINTINALHA², Niels Vinicius Pádua CARVALHO²

\begin{abstract}
Background: About $50 \%$ of patients that suffer from trigeminal neuralgia do not experience sustained benefit from the use of oral medication. For their adequate management, a few surgical procedures are available. Of these, percutaneous balloon compression (PBC) and microvascular decompression (MD) are two of the most performed worldwide. In this retrospective study, we present the outcomes of these techniques through estimation of initial pain relief and subsequent recurrence rate. Methods: Thirty-seven patients with medically refractory trigeminal pain surgically treated at Hospital Cajuru, Curitiba, Brazil, with PBC, MD or both between 2013 and 2018 were enrolled into this retrospective study. The post-procedural rate for pain relief and recurrence and associations between patient demographics and outcomes were analyzed. Results: MD had an earlier recurrence time than balloon compression. Of the 37 patients, the mean age was 61.6 years, approximately one third were male and most had type I neuralgia. The most affected branch was the maxillary (V2). The time for recurrence after surgery was on average 11.8 months for PBC and 9.0 months for MD. Complications were seen only with microsurgery. Conclusions: MD presented with a more precocious recurrence of pain than PBC in this article. Moreover, it had a higher recurrence rate than described in the literature as well, which is possibly explained by the type of graft (muscle) that was used to separate the neurovascular structures.
\end{abstract}

Keywords: Microvascular Decompression Surgery; Trigeminal Neuralgia; Intractable Pain.

\begin{abstract}
RESUMO
Introdução: Cerca de 50\% dos pacientes com neuralgia do trigêmeo não apresenta benefícios a longo prazo com o uso de medicação oral. Para a manutenção do tratamento, algumas opções cirúrgicas estão disponíveis, sendo a compressão percutânea por balão (CPB) e a descompressão microvascular (DM) algumas das modalidades mais realizadas em todo o mundo. Neste estudo retrospectivo, apresentamos os desfechos dessas técnicas por meio de estimativa da melhora inicial da dor e da taxa de recorrência subsequente. Métodos: Trinta e sete pacientes com dor trigeminal refratária ao tratamento medicamentoso tratados cirurgicamente no Hospital Cajuru, Curitiba, Brasil, com CPB, DM ou ambos entre 2013 e 2018 foram incluídos neste estudo retrospectivo. A taxa pós-procedimento para alívio e recorrência da dor e suas associações com a demografia e desfechos dos pacientes foram analisadas. Resultados: A DM foi associada a menor recorrência que a compressão por balão. Entre os 37 pacientes, a idade média foi de 61,6 anos, aproximadamente um terço eram do sexo masculino e a maioria apresentava neuralgia do tipo I. O ramo mais afetado foi o maxilar (V2). 0 tempo de recorrência após a cirurgia foi em média de 11,8 meses para CPB e 9,0 meses para DM. Foram vistas complicações apenas na microcirurgia. Conclusões: A DM apresentou recidiva mais precoce da dor em comparação à CPB. Além disso, apresentou uma taxa de recorrência mais alta do que a descrita na literatura, o que é possivelmente explicado pelo tipo de enxerto (músculo) usado para separar as estruturas neurovasculares.
\end{abstract}

Palavras-chave: Cirurgia de Descompressão Microvascular; Neuralgia do Trigêmeo; Dor Intratável.

'Hospital Universitário Cajuru, Curitiba PR, Brazil.

¿Universidade Positivo, Curitiba PR, Brazil.

Jennyfer Paulla Galdino CHAVES (D) https://orcid.org/0000-0003-2453-5205; Tatiana Von Hertwig Fernandes DE OLIVEIRA (DD https://orcid.org/0000-0002-7242-7551; Alexandre Novick FRANCISCO (D) https://orcid.org/0000-0003-2039-6834; Mariana de Oliveira TRINTINALHA (D) https://orcid.org/0000-0002-4471-5695; Niels Vinicius Pádua CARVALHO (DD https://orcid.org/0000-0001-9892-9798

Conflict of interest: There is no conflict of interest to declare.

Authors' contributions: JPGC: investigation, methodology, supervision, validation, writing-original draft and writing-review \& editing. TVHFO: conceptualization, investigation, methodology, project administration, supervision, writing-original draft and writing-review \& editing. AFN: conceptualization, investigation, project administration and supervision. MOT: investigation, methodology and writing-original draft. NVPC: funding acquisition, investigation, methodology and writing-original draft.

Received on March 24, 2020; Received in its final form on May 18, 2020; Accepted on June 15, 2020. 
The trigeminal nerve (TN) neuralgia is a neuropathic facial pain described as a severe, paroxysmal, shock-like sensation in the distribution of one or more trigeminal roots, usually unilateral and ipsilateral to the branch of the affected $\mathrm{TN}^{1}$. Trigeminal neuralgia can be classified as classical (idiopathic), symptomatic or atypical. The clinical characteristics are similar in idiopathic and symptomatic forms, but in the latter it is associated with structural lesions, such as vascular compression, multiple sclerosis and tumors. Otherwise, in the atypical form, the patient presents with a paroxysmal component coupled with a continuous, burning pain².

The TN has 3 sensory branches, known as ophthalmic (V1), maxillary (V2) and mandibular (V3). The V1 branch is responsible for the innervation of the ocular, supraciliar, frontal and upper nasal areas; V2, for the zygomatic, upper teeth, lateral nose, lower eyelid and upper lip areas; and V3, for the mandible and the temporomandibular joint area. According to van Kleef et al., V2 and V3 are the most commonly affected branches, with a rate of $32 \%$, followed by involvement of only $\mathrm{V} 2$ or all branches with $17 \%$ prevalence ${ }^{3}$. The least involved branch is V1 (4\%) ${ }^{4}$. Trigeminal neuralgia is the most common cranial neuropathy, with an annual prevalence of 4.3 people per 100,000 population, being more common in women than in men (5.7 versus $2.5 \%$ per 100,000 inhabitants), as well in advanced ages (11 cases per $100,000$ people over 75 years) $)^{5}$.

Trigeminal neuralgia can be treated pharmacologically or surgically. The most used drugs for pain control are carbamazepine, an antiepileptic, which has a level of evidence II, as well as botulinum toxin. Other medications as phenytoin, gabapentin and amitriptyline may be used additionally. When medical treatment fails, surgical options such as percutaneous procedures, stereotactic radiosurgery and microvascular decompression (MD) should be considered. Percutaneous techniques include percutaneous rhizotomy by radiofrequency, which consists on a thermal injury of the trigeminal ganglion; balloon compression, characterized by a mechanical lesion of the ganglion; and percutaneous rhizotomy with glycerol, which provokes demyelination and axonal fragmentation of pain fibers through a chemical lesion ${ }^{6,7,89}$. Gamma knife surgery, a destructive procedure as well, consists on a focused beam of radiation that is aimed at the trigeminal root in the posterior fossa ${ }^{10}$. MD, diversely, is an invasive procedure that allows direct visualization and treatment of the vascular conflict ${ }^{10}$.

Among all surgical procedures, $\mathrm{MD}$ is considered the most effective and the first-line surgical treatment option for these patients, because, although more invasive than others, it is considered safe as primary line of surgery, but not for subsequent interventions, due to adhesion in arachnoid and distortion of the normal anatomy of the region ${ }^{9,11}$.

This study aimed at comparing the outcomes of two of the most used surgical techniques in the treatment of trigeminal neuralgia (percutaneous balloon compression $[\mathrm{PBC}]$ and $\mathrm{MD}$ ), with focus on pain recurrence rates.

\section{METHODS}

\section{Patient selection}

This study is a retrospective analysis of 37 patients with pain recurrence after surgical treatment of trigeminal neuralgia at our institution. The data was collected through chart review of all patients who underwent MD, percutaneous balloon compression or both procedures in the last 5 years ( from 2013 to 2018). All patients treated surgically were refractory to medical treatment with gabapentin, carbamazepine, amitriptyline and phenytoin, and all procedures were performed by two neurosurgeons (TO or $\mathrm{AF}$ ) using the same technique. The type of pain was characterized as type 1 or 2 . TN type 1 is characterized by attacks of intense, stabbing pain affecting the mouth, cheek, nose, and/or other areas on one side of the face, while TN type 2 is characterized by less intense pain, but a constant dull aching or burning pain. The selection criteria for $\mathrm{PBC}$ or MD was based in the patient choice; usually the elderly patients opted for a minimally invasive method. Recurrence was defined by an increase of pain level that required reinitiation of medication or reoperation after an initial improvement.

\section{Procedures}

PBC was performed at the hemodynamic suite using either general anesthesia with an endotracheal tube or sedation with a laryngeal mask. The entry point was defined by direct visualization of the ovale foramina with fluoroscopic guidance, medial to the ramus of the mandible and lateral to the maxillary sinus. Ten cc of local anesthetic were injected at the site to decrease the risk of penetrating the oral cavity. A 14-gauge cannula was used to perforate the skin and was advanced until the inferior border of the foramina. The needle was then engaged and the fluoroscopy image was repositioned to allow for visualization of the sphenoidal plane. When the needle tip was aligned to this plane, a Fogarty 4F catheter was advanced through the needle and insufflated with soluble contrast until it assumed a pear or hourglass shape. The compression was maintained for 60 seconds. The balloon was then deflated and removed with the cannula.

MD was performed at the park bench position. No lumbar drain was placed before the procedure. A linear incision at the suboccipital region was undertaken, and a retrosigmoid craniotomy was performed. The cerebellopontine angle was accessed after cerebellar retraction, the VII/VIII complex was exposed and its pia was dissected to avoid retraction. Deeper, the V nerve was identified, along with the neurovascular conflict. A trigeminal root massage was performed. A muscle graft from the suboccipital musculature was used to separate the vascular structures from the nerve. The dura 
mater was closed in a watertight fashion, and the bone was fixed with titanium plates.

\section{Follow-up evaluations}

Follow-up visits were scheduled at months 1, 3, 6 and 12 after the procedures. Data pertaining to the degree of pain relief, pain free interval, need for further surgical intervention and medications in use were obtained.

\section{Data and analyses}

Data was collected using Excel (Microsoft Corp.) and analyzed using Statistical Package for the Social Science (SPSS).

Patient demographics and outcomes were analyzed using descriptive statistics. Pain recurrence rates were analyzed by the following methods: Student's t-test, Mann-Whitney, Chisquared test and Kaplan Meier. A p $<0.05$ was considered statistically significant.

\section{RESULTS}

\section{Demographics}

The demographics of our series is outlined at Table 1. Of the 37 patients who underwent surgical procedures and experience pain recurrence, approximately one third were

Table 1. Demographics of our series, showing total of patients, mean age, distribution, side and type of pain.

\begin{tabular}{lcc} 
& \multicolumn{2}{c}{ Demographic rate } \\
\cline { 2 - 3 } & Value & $\%$ \\
\hline Total of patients & 37 & \\
$\quad$ Female & 25 & 67.5 \\
Male & 12 & 32.4 \\
Age (years) & \multicolumn{2}{c}{ (30-78) } \\
Mean & \multicolumn{2}{c}{ (30) } \\
Range & \multicolumn{2}{c}{ (30) }
\end{tabular}

\section{Distribution}

\begin{tabular}{lcc} 
V1 & 1 & 2.7 \\
V2 & 3 & 8.1 \\
V3 & 8 & 21.6 \\
V1, V2 & 5 & 13.5 \\
V2, V3 & 10 & 27.0 \\
V1, V2, V3 & 9 & 24.3 \\
V1, V2, V3 other & 1 & 2.7 \\
Side of pain & & \\
Right & 21 & 56.7 \\
Left & 16 & 43.2 \\
Type op pain & & \\
I & 31 & 83.7 \\
II & 6 & 16.2 \\
\hline
\end{tabular}

male and most had type I neuralgia. The most affected branches were V2 and V3, and only one patient had bilateral neuralgia. Neurovascular conflict (NVC) in the magnetic resonance imaging (MRI) was identified in approximately one third of patients.

We found that six patients (of a total of 14) had recurrence 9.0 months after $\mathrm{MD}$ and 15 patients (of a total of 23) had recurrence 11.8 months after PBC as shown in Tables 2 and 3. Two patients submitted to $\mathrm{MD}$ who had recurrence also underwent PBC.

\section{Pain response}

Table 2 details the treatment data of 37 patients who underwent $\mathrm{PBC}$ or $\mathrm{MD}$. The $\mathrm{p}$ value for the recurrence rate in $\mathrm{PBC}$ or MD (0.508), as well as the p value for the time of recurrence (0.381), was not significative.

Twelve patients had NVC on the MRI, being the most involved vascular structures the superior cerebellar artery, basilar dolichoectasia and anterior inferior cerebellar artery. All patients with NVC underwent surgical treatment, and only 3 experienced pain recurrence $(p=0.029)$. The Kaplan Meier survival test comparing type of surgery (PBC or MD), time for recurrence in months and the presence of recurrence is represented in Figure 1.

\section{Complications}

Two patients had complications after MD: an extradural hematoma and a transitory peripheral facial palsy. No complication was observed after percutaneous balloon compression.

Table 2. Distribution of the patients which underwent microvascular decompression and percutaneous balloon compression and their recurrence.

\begin{tabular}{ccc}
\hline \multicolumn{3}{c}{ Recurrence after surgery } \\
\hline Surgery/recurrence & Value & $\%$ \\
\hline Balloon & 23 & 62.1 \\
No & 10 & 43.5 \\
Yes & 13 & 56.5 \\
Decompression & 14 & 37.8 \\
No & 8 & 57.1 \\
Yes & 6 & 42.9 \\
\hline Total & 37 & 100 \\
\hline
\end{tabular}

Table 3. Mean time for recurrence in microvascular decompression and percutaneous balloon compression.

\begin{tabular}{lcc}
\hline \multicolumn{3}{c}{ Time for recurrence after surgery } \\
\hline Recurrence & Patients & Mean (MO) \\
\hline Ballon & 15 & 11.8 \\
Decompression & 6 & 9.0 \\
\hline
\end{tabular}

MO: months. 


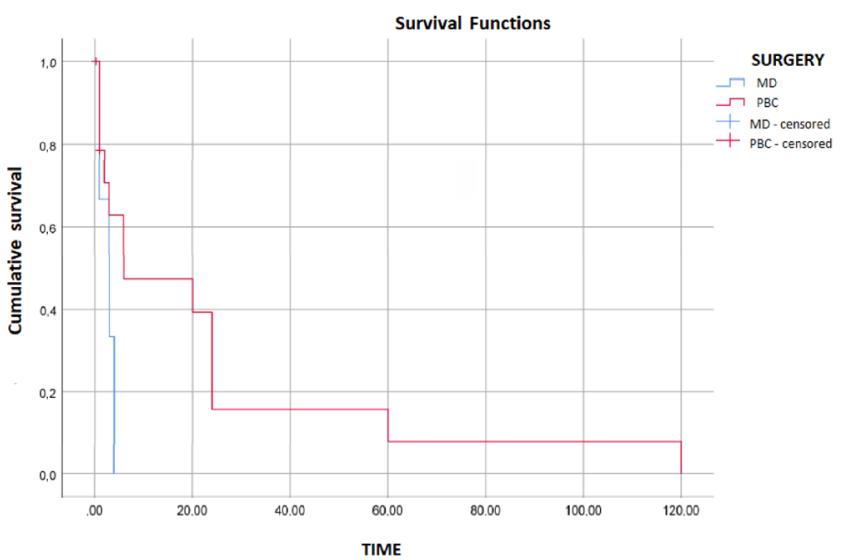

MD: microvascular decompression; PBC: percutaneous balloon compression. Figure 1. Kaplan-Meier survival test comparing type of surgery, time for recurrence in months and the presence of recurrence.

\section{DISCUSSION}

We sought to compare PCB and MD for the treatment of $\mathrm{TN}$ in the terms of response to treatment and its longevity. After surgical treatment of this condition, a fairly large spectrum of potential outcomes exists from being completely pain-free and off of medication to no improvement, or, on rare occasions, worsening of these debilitating pain attacks ${ }^{3}$.

Although vascular compression of the TN root entry zone is widely accepted as TN etiology, it fails to explain why some patients have TN without an identifiable NVC, as the main believed factor for proper decompression is the correct exposure of the root entrance zone $\mathrm{e}^{12,13}$. This is an important consideration, as patients who had NVC in the MRI, in our practice, had a lower recurrence rate. However, it should be noted that even patients without identifiable NVC on the MRI could still appreciate complete resolution of symptomatology after surgical procedures ${ }^{13,14}$. Other negative factors that may influence recurrence are type II TN, disease duration, gender (female), bilateral involvement and multiple sclerosis ${ }^{15}$.

In the literature, the recurrence rate in $\mathrm{PBC}$ is relatively high and ranges from 20 to $64 \%^{16}$, which is in agreement with our findings (56.5\%). Although initial response to $\mathrm{PBC}$ is 82-93.8\%, it decreases overtime to $75-90 \%$ after 1 year, $44-65 \%$ after 5 years, and $30-51.5 \%$ after 10 years ${ }^{15}$. In a systematic review conducted by Mendelson et al., it was found that MD was more effective in remission of the pain when compared to Gamma Knife ${ }^{17}$. Likewise, a longitudinal study carried out with medical records of patients at the University of California concluded that pain improvement was more lasting and effective with $\mathrm{MD}^{18}$. Chen et al. carried out a prospective cohort with 110 patients with recurrent TN and found, like the other authors, that MD shows rates of immediate pain improvement and also lower incidences on long-term complications ${ }^{19}$.

Balloon shape, its location and internal volume, as well as compression duration, are parameters that affect $\mathrm{PBC}$ recurrence rate and immediate outcome ${ }^{12}$. Otherwise, in MD, it ranges from 0 to $29 \%^{20,21}$, which is almost half of the rate of our series. The main reason for unsuccessful decompression is unsatisfactory exposition of the root entry zone or the axilla of the nerve, regions that are more difficult to access, leaving compression areas concealed ${ }^{15}$. In cases of hypertrophic petrous bone, it may be necessary to drill the area to achieve an adequate exposure and, consequently, decompression ${ }^{14}$. Another possible explanation to the high recurrence rate in our practice may be related to the muscle patch is used to withdraw the vessels from the nerve as we, unfortunately, do not have access to non-absorbable patches as Teflon.

Complications of PBC include hearing loss, which occurs in 2.4 to $6.3 \%$ of cases, masseter weakness, cheekbones and aseptic meningitis ${ }^{15}$. Hypotension and bradycardia due to the trigeminal reflex are also described and, among all percutaneous procedures for $\mathrm{TN}, \mathrm{PBC}$ has the highest rate. The major MD complication was aseptic meningitis, followed by longterm hearing loss and long-term sensory loss. A study by Gronseth et al. showed that $11 \%$ of patients suffered from aseptic meningitis, while $10 \%$ had hearing loss and $7 \%$ sensory loss. The average mortality rate was approximately $0.2 \%$, while other major events, like hematoma, infarctions and cerebrospinal fluid leaks, happened in up to $4 \%$ of the cases.

The PCB technique had best long-term outcome with no complications in relation to the MD in our study, which diverge from the results in literature. We believe this is related with the muscle patch we used in the MD. After this study, our practice changed. Nowadays, we are able to use non-absorbable patches, and the results will be compared in a future date.

In conclusion, from the analysis of the data, it is possible to conclude that our results are distinct from the literature, as pain recurrence is earlier after microvascular procedure than PBC, which is probably related to the absorbable material that is used in our practice. However, to confirm this finding, more specific investigation should be conducted. Therefore, a randomized clinical trial would be necessary to elucidate the role of muscle graft in pain recurrence of trigeminal neuralgia in patients submitted to MD.

\section{References}

1. Frizzo HM, Veronese RM. Trigeminal neuralgia: an analytic review of the literature. Rev Cir Traumatol Buco-Maxilo-Fac. 2004;4(4):212-7.

2. Headache Classification Committee of the International Headache Society (IHS). The International Classification of Headache Disorders, 3rd edition (beta version). Cephalalgia. 2013 Jul;33(9):629-808. https://doi.org/10.1177/0333102413485658

3. van Kleef M, van Genderen WE, Narouze S, Nurmikko TJ, van Zundert J, Geurts JW, et al. 1. Trigeminal neuralgia. Pain Pract. Jul-Aug 2009;9(4):252-9. https://doi.org/10.1111/j.1533-2500.2009.00298.x 
4. Cheshire JrWP. Cranial neuralgias. Continuum (Minneap Minn). 2015 Aug;21(4 Headache):1072-85. https://doi.org/10.1212/ CON.0000000000000194

5. Posso IP, Palmeira CCA, Vieira EBM. Epidemiologia da dor neuropática. Rev Dor. 2016;17(Suppl 1):11-4. http://dx.doi. org/10.5935/1806-0013.20160039

6. Burchiel KJ, Totah A, Zachariah SB. Trigeminal neuralgia surgery. Available from: 〈http://emedicine.medscape.com/article/248933overview\#a3>

7. Zeme S. The surgical treatment of trigeminal neuralgia.J Pain Relief. 2016;(4):6. https://doi.org/10.4172/2167-0846.S4-006

8. Montano N, Conforti G, Bonaventura R, Meglio M, Fernandez E, Papacci F. Advances in diagnosis and treatment of trigeminal neuralgia. Ther Clin Risk Manag. 2015;11:289-99. https://doi. org/10.2147/TCRM.S37592

9. Gronseth G, Cruccu G, Alksne J, Brainin M, Burchiel K, Nurmikko T, et al. Practice parameter: the diagnostic evaluation and treatment of trigeminal neuralgia (an evidence-based review) Report of the Quality Standards Subcommittee of the American Academy of Neurology and the European Federation of Neurological Societies. Neurology. 2008 Oct;71(15):1183-90. https://doi.org/10.1212/01. wnl.0000326598.83183.04

10. Obermann, M. Treatment options in trigeminal neuralgia. Ther Adv Neurol Disord. 2010 Mar;3(2):107-15. https://doi. org/10.1177/1756285609359317

11. Xu W, Jiang C, Yu C, Liang W. Percutaneous balloon compression for persistent or recurrent trigeminal neuralgia after microvascular decompression: personal experience of 28 patients. Acta Neurol Belg. 2018 Dec;118(4):561-6. https://doi.org/10.1007/s13760-0170858-8

12. Ying $X$, Wang $H$, Deng S, Chen Y, Zhang J, Yu W. Long-term outcome of percutaneous balloon compression for trigeminal neuralgia patients older than 80 years: A STROBE-compliant article. Medicine (Baltimore). 2017 Sep;96(39):e8199. https://doi.org/10.1097/ MD.0000000000008199

13. Inoue T, Goto Y, Prasetya M, Fukushima T. Resection of the suprameatal tubercle in microvascular decompression for trigeminal neuralgia. Acta Neurochir (Wien). 2020 May;162(5):1089-94. https:// doi.org/10.1007/s00701-020-04242-8

14. Sarsam Z, Garcia-Fiñana M, Nurmikko TJ, Varma TR, Eldridge P. The longterm outcome of microvascular decompression for trigeminal neuralgia. Br J Neurosurg. 2010 Feb;24(1):18-25. https://doi. org/10.3109/02688690903370289

15. Bick SKB, Eskandar EN. Surgical treatment of trigeminal neuralgia. Neurosurg Clin N Am. 2017 Jul;28(3):429-38. https://doi. org/10.1016/j.nec.2017.02.009

16. Kouzounias K, Schechtmann G, Lind G, Winter J, Linderoth B. Factors that influence outcome of percutaneous balloon compression in the treatment of trigeminal neuralgia. Neurosurgery. 2010 Oct;67(4):92534; discussion 934. https://doi.org/10.1227/NEU.0b013e3181eb5230

17. Mendelson ZS, Velagala JR, Kohli G, Heir GM, Mammis A, Liu JK. Pain free outcomes and durability of surgical intervention for trigeminal neuralgia: a comparison of gamma knife and microvascular descompression. World Neurosurg. 2018 Apr;112:e732-e746. https:// doi.org/10.1016/j.wneu.2018.01.141

18. Wang DD, Raygor KP, Cage TA, Ward MM, Westcott S, Barbaro NM, et al. Prospective comparison of long-term pain relief rates after first-time microvascular decompression and stereotactic radiosurgery for trigeminal neuralgia. J Neurosurg. 2018; 128(1): 68-77.

19. Chen JN, Yu WH, Du HG, Jiang L, Dong XQ, Cao J. Prospective comparison of redo microvascular decompression and percutaneous balloon compression as primary surgery for recurrent trigeminal neuralgia.J Korean Neurosurg Soc. 2018 Nov;61(6):747-52. https:// doi.org/10.3340/jkns.2017.0196

20. Yang XS, Li ST, Zhong J, Zhu J, Du Q, Zhou QMJ, et al. Microvascular decompression on patients with trigeminal neuralgia caused by ectatic vertebrobasilar artery complex: technique notes. Acta Neurochir (Wien). 2012 May;154(5):793-7; discussion 797. https://doi. org/10.1007/s00701-012-1320-6

21. Sarsam Z, Garcia-Finana M, Nurmikko TJ, Varma TR, Eldridge P. The longterm outcome of microvascular decompression for trigeminal neuralgia. Br J Neurosurg. 2010 Feb;24(1):18-25. https://doi. org/10.3109/02688690903370289 